\title{
Achievement of a target dose of bisoprolol may not be a preferred option for attenuating pressure overload-induced cardiac hypertrophy and fibrosis
}

\author{
SHIZHAO XIANG ${ }^{1,2}$, NING ZHANG $^{1,2}$, ZHENG YANG $^{1,2}$, ZHOUYAN BIAN $^{1,2}$, YUAN YUAN $^{1,2}$ and QIZHU TANG $^{1,2}$ \\ ${ }^{1}$ Department of Cardiology, Renmin Hospital of Wuhan University; \\ ${ }^{2}$ Cardiovascular Research Institute of Wuhan University, Wuhan, Hubei 430060, P.R. China
}

Received March 10, 2015; Accepted June 6, 2016

DOI: $10.3892 / e t m .2016 .3570$

\begin{abstract}
Bisoprolol is a drug that acts via the mechanism of specifically and selectively inhibiting the $\beta_{1}$-adrenoreceptor in cardiac myocytes, and provides a pure reduction of heart rate without changing other cardiac parameters. It has long been clinically used to treat cerebrovascular and cardiovascular illnesses. However, there is little information available on whether the role of bisoprolol in the attenuation of ventricular remodeling is dependent upon the achievement of a target dose, and whether it must be used as a preferred option. The aim of the present study was to clarify the underlying benefits of bisoprolol in the attenuation of pressure overload-induced cardiac hypertrophy and fibrosis at different doses. C57BL/6J male mice, aged 6-8 weeks, were treated with saline or one of three different doses of bisoprolol (Biso: 2.5, 5 or $10 \mathrm{mg} / \mathrm{kg} /$ day) for 8 weeks from day 1 after aortic banding (AB). A number of mice underwent sham surgery and were treated with saline or bisoprolol. The mice were randomly assigned into the sham $(n=24)$ and AB $(n=62)$ groups. The results revealed that bisoprolol had a protective role against the cardiac hypertrophy, fibrosis and dysfunction caused by $\mathrm{AB}$. This was determined on the basis of heart/body and lung/body weight ratios and heart weight/tibia length ratios, as well as echocardiographic and hemodynamic parameters, histological analysis, and the gene expression levels of hypertrophic and fibrotic markers. The present study revealed that administration of bisoprolol for a long time period may enhance its role in the prevention of cardiac hypertrophy and fibrosis induced by AB, whereas no statistically significant difference was observed between the middle- and high-doses. These observations indicated that the function of bisoprolol in protecting against cardiac hypertrophy,
\end{abstract}

Correspondence to: Dr Qizhu Tang, Department of Cardiology, Renmin Hospital of Wuhan University, 238 Jiefang Road, Wuhan, Hubei 430060, P.R. China

E-mail: qztang@whu.edu.cn

Key words: bisoprolol, $\beta$ adrenoreceptor blocker, cardiac fibrosis, cardiac hypertrophy fibrosis and dysfunction is time-dependent. Furthermore, it is proposed that a middle dose of bisoprolol may be a better option for patients with cardiovascular illnesses, particularly those undertaking coronary artery bypass graft and cardiac pacemaker surgeries. These promising results require further clinical investigation.

\section{Introduction}

Heart failure (HF) is a syndrome in which the quantity of blood being pumped by the heart is insufficient to meet the requirements of the body. A failing heart usually results in progressive functional decline, irrespective of the cause of its failure. HF has high prevalence, mortality and morbidity rates, as well as significant healthcare costs, and so is an important health problem worldwide. Atherothrombotic illnesses, which often lead to HF, are predicted to increase in prevalence and become the primary cause of mortality worldwide by 2020 , thus contributing to an increase in the prevalence of HF (1).

Elevated sympathetic nervous system activity in patients with $\mathrm{HF}$ is associated with a poor survival rate (2). Although $\mathrm{HF}$ improves the contractility of the heart, sustained activation of $\beta$-adrenergic receptors ( $\beta$-ARs), particularly of the $\beta_{1}$ subtype, causes contractile dysfunction, arrhythmias of the ventricle, cell loss, cardiac chamber remodeling and congestive heart failure (2). The resultant cardiac histology is characterized by hypertrophy of cardiomyocytes, in addition to perivascular and concomitant interstitial fibrosis (2). Certain $\beta$-adrenergic blockers, when given as long-term treatment, have shown the ability to attenuate ventricular remodeling (3). Bisoprolol is a selective and specific blocker of $\beta_{1}$-ARs in cardiac myocytes, and selectively reduces the heart rate without changing any other cardiac parameters, such as conduction. Furthermore, bisoprolol has no direct effect on other hemodynamic parameters (3). Previous studies have demonstrated that bisoprolol has several pharmacological functions, including anti-anginal, anti-arrhythmic and anti-ischemic functions, and it is clinically used for the treatment of cerebrovascular and cardiovascular illnesses (4).

The up-titration of $\beta$-blockers is often suboptimal in clinical practice (5). It is commonly observed that patients not only do not take the target dose as stated in the guidelines but also 
cease to take the pills due to a fear of the side effects. From a doctor's perspective, the administration of a medium dose of a $\beta$ blocker to patients with cardiovascular disease, particularly those who are due to undergo coronary bypass graft or cardiac pacemaker surgeries, may be safer than up-titration. However, there is little information available with regard to whether the role of bisoprolol in attenuating ventricular remodeling is dependent on the achievement of a target dose, and whether this should be the preferred option. The aim of the present study was to clarify the underlying benefits of bisoprolol in the attenuation of pressure overload-induced cardiac hypertrophy and fibrosis among different doses of the drug in mice.

\section{Materials and methods}

Animal models. All animal procedures were performed in accordance with the Guide for the Care and Use of Laboratory Animals published by the US National Institutes of Health (NIH Publication No. 85-23, revised 1996) and approved by the Institutional Animal Care and Use Committee at Renmin Hospital of Wuhan University (Wuhan, China). All surgeries and subsequent analyses were performed in a blinded manner. Experiments were conducted using 6-8-week-old male C57BL/6J mice (11400700047102; Beijing Vital River Laboratory Animal Technology Co., Ltd., Beijing, China) weighing between 20-25 g $(n=62)$ were used in these experiments. The mice were kept in a quiet, clean and dim feeding specific pathogen free system with a 12-hour light:dark cycle at a constant temperature of $22^{\circ} \mathrm{C}$, and they had free access to clean water from an inverted plastic bottle. The mice also had access to rodent chow and to fresh air that was ventilated using a small VFA-23-BV animal ventilator (Kent Scientific, Connecticut, USA). Aortic banding (AB) was performed as previously described (6). The mice were randomly assigned into the following six groups: Bisoprolol $(10 \mathrm{mg} / \mathrm{kg} / \mathrm{day})+$ sham $(\mathrm{n}=12)$, saline + sham $(\mathrm{n}=12)$, $\mathrm{AB}+$ saline $(\mathrm{n}=14), \mathrm{AB}+$ low-dose bisoprolol $(2.5 \mathrm{mg} / \mathrm{kg} / \mathrm{day}$; $\mathrm{n}=16), \mathrm{AB}+$ middle-dose bisoprolol $(5 \mathrm{mg} / \mathrm{kg} / \mathrm{day} ; \mathrm{n}=16)$ and $\mathrm{AB}+$ high-dose bisoprolol (10 mg/kg/day; $\mathrm{n}=16)$. Bisoprolol and inert saline were administered orally via gastric gavage for 8 weeks starting on day 1 following surgery.

The mice were fasted during the night prior to surgery. A topical depilatory agent was applied to the neck and chest area to remove fur at and around the area of the incision. One dose of penicillin $(10 \mathrm{mg} / \mathrm{kg}, 0.1 \mathrm{ml})$ was administered by an intraperitoneal (i.p.) injection prior to the beginning of surgery. Next, the mice were placed supine and the body temperature was maintained at $37^{\circ} \mathrm{C}$ using a heating pad. The mice were then anesthetized with sodium pentobarbital $(80 \mathrm{mg} / \mathrm{kg}$, i.p.; Sigma-Aldrich, St. Louis, MO, USA) and xylazine (10 mg/kg). Following endotracheal intubation, mechanical ventilation was initiated. The skin was cleaned with Germex and Betadine (both from Winguide Huangpu Pharmaceutical Co., Ltd., Shanghai, China). A horizontal skin incision of $1 \mathrm{~cm}$ in length was made at the level of 2-3 intercostal spaces, once the animal reached a surgical plane of anesthesia (lack of reflex or response to toe-pinching). A 6-0 silk suture was snared and pulled back around the aorta to produce a $65-70 \%$ constriction following removal of the needle. A bent 27-gauge needle (for 23.5-25.5 g) was then placed next to the aortic arch and the suture was tightly tied around the needle and aorta between the left carotid artery and the brachiocephalic trunk. Doppler analysis was performed to ensure that a physiological constriction of the aorta was induced. Following ligation, the needle was quickly removed allowing the suture to constrict the aorta. The incision was closed in layers and the mice were allowed to recover on a warming pad until they were fully awake. The adequacy of anesthesia was monitored during the surgical procedure using the pedal withdrawal reflex, slow constant breathing and the lack of a response to surgical manipulation. The sham animals underwent the same procedure without AB.

Immediately after the surgery, mice received one dose of buprenorphine $(0.1 \mathrm{mg} / \mathrm{kg}$, subcutaneously) for the first $24 \mathrm{~h}$, and were allowed to have food and water when they were fully awake. On day 1 after the surgery, the administration of bisoprolol was initiated.

Drugs and reagents. Bisoprolol was purchased from Merck KGaA (Frankfurt, Germany). The following antibodies were used: Anti-glyceraldehyde 3-phosphate dehydrogenase (2118; anti-GAPDH; Cell Signaling Technology, Inc., Danvers, MA, USA), anti-atrial natriuretic peptide (sc20158; ANP), anti-brain natriuretic peptide (18817; BNP), anti- $\beta$-myosin heavy chain (sc53090; MHC) (all from Santa Cruz Biotechnology, Inc., Dallas, TX, USA), and anti-connective tissue growth factor (23936; CTGF), anti-transforming growth factor (TGF)- $\beta_{1}$ (3709) and anti-collagen 1a (ab90395) (all from Abcam, Cambridge, UK).

Echocardiographic imaging. After 4 and 8 weeks, mice that had been subjected to chronic pressure overload generated by $\mathrm{AB}$ or to sham surgery, the latter serving as a control group, were subjected to echocardiographic imaging. Transthoracic M-mode and Doppler echocardiographic examination was performed using a MyLab $30 \mathrm{CV}$ ultrasound instrument (Esaote SpA, Genoa, Italy) with a $10 \mathrm{MHz}$ linear array ultrasound transducer, as previously described, in order to assess the internal diameter and wall thickness of the left ventricle (LV) $(7,8)$. Mice were placed on a heating pad and a nose cone with $0.75-1 \%$ isoflurane in $100 \%$ oxygen was applied. The temperature was maintained at $36.5-37.5^{\circ} \mathrm{C}$ and ultrasound gel was spread on the chest of the anesthetized mouse. The ultrasound probe was placed in contact with the ultrasound gel and scanning was performed over a period of $30 \mathrm{~min}$. The heart rate, temperature and blood pressure were constantly monitored during the scan, and M-mode images were obtained for measurements of the LV wall thickness, LV end-diastolic diameter (LVEDD), LV end-systolic diameter (LVESD), left ventricular septum diastolic (IVSD), left ventricular posterior wall diameter (LVPWD), fractional shortening (FS) and ejection fraction $(\mathrm{EF})$. The data were stored on a hard drive and a $230 \mathrm{MB}$ optical disk for image processing.

Hemodynamic analysis. The in vivo cardiac performance was measured by both load-dependent and load-independent parameters derived from pressure-volume (P-V) loops. The invasive hemodynamic measurements were performed by the same operator who was blinded to the experimental groups following the echocardiographic examination in each mouse. The mice were anesthetized with $1.5 \%$ isoflurane using cardiac 
catheterization. A SPR-839 microtip catheter transducer (Millar Instruments, Houston, TX, USA) was inserted into the right carotid artery and moved into the LV. Following stabilization for a period of $15 \mathrm{~min}$, the pressure signals and heart rate were continuously recorded with an ARIA pressure-volume conductance system (MVPS-400, Millar, Inc., TX, USA) coupled with a Powerlab/4SP A/D converter (ATC1000; World Precision Instruments Inc., Hilton, Australia) and then stored and displayed on a personal computer as previously described $(7,8)$.

The mice were sacrificed by cervical dislocation 8 weeks post-operatively after anesthetizing with $1.5 \%$ isoflurane (Lunan Pharmaceutical Group Co., Ltd., Shandong, China) or sodium pentobarbital ( $80 \mathrm{mg} / \mathrm{kg}$; i.p; Sigma-Aldrich). The hearts, lungs and tibiae of the mice were dissected and weighed or measured to compare the heart weight $(\mathrm{HW}) /$ body weight (BW) in $\mathrm{mg} / \mathrm{g}, \mathrm{HW} /$ tibial length (TL) in $\mathrm{mg} / \mathrm{mm}$, and lung weight $(\mathrm{LW}) / \mathrm{BW}$ in $\mathrm{mg} / \mathrm{g}$ ratios amongst the different groups.

Histological and morphometric analysis. All morphometric and histological measurements were obtained from the hearts arrested in diastole (intracardiac $40 \mathrm{mM} \mathrm{KCl}$ ), rinsed with saline solution and placed in $10 \%$ formalin. The sections were deparaffinized in xylene and rehydrated in ethanol. The hearts were transversely sectioned close to the apex in order to visualize the left and right ventricles. Numerous sections (4-5 $\mu \mathrm{m}$ thick) were prepared and stained with hematoxylin and eosin (H\&E) for histopathology or with picrosirius red (PSR) for interstitial and perivascular collagen volume fraction quantification. The stained sections were visualized by light microscopy at magnification, $x 400$, and cross-sectional images of the cardiac myocytes were digitized using an Eclipse 80i digital microscope (Nikon Corporation, Tokyo, Japan). An quantitative digital image analysis system (Image-Pro Plus 6.0, Media Cybernetics, Inc., Rockville, MD, USA) was used to measure single myocytes, with 100-200 myocytes in the LV being outlined in each group. The fraction of collagen was calculated as a ratio of the sum of the total area of interstitial or perivascular fibrosis to the sum of the total connective tissue area plus the myocyte area in the entire visual field of a section. For myocyte cross-sectional area, the sections were stained for membranes with fluorescein (FITC)-conjugated wheat germ agglutinin (WGA; Invitrogen, Thermo Fisher Scientific, Inc., Waltham, MA, USA) and for nuclei with 4',6-diamidino-2-phenylindole according to standard protocols (9).

Reverse transcription-quantitative polymerase chain reaction (RT-qPCR) analysis. RT-qPCR was used to detect the RNA expression levels of fibrotic and hypertrophic markers. The total RNA was extracted from flash-frozen, pulverized mouse cardiac tissue using the TRIzol (Roche Diagnostics, Basel, Switzerland) extraction protocol. A SmartSpec plus spectrophotometer (Bio-Rad Laboratories, Inc., Hercules, CA, USA) was used to estimate the yield and purity using the A260/A280 and A230/260 ratios. The RNA ( $2 \mu \mathrm{g}$ of each sample) was reverse transcribed into cDNA using oligo (dT) primers and RTase (04897030001; Roche Diagnostics GmbH, Mannheim, Germany) and the Transcriptor First Strand cDNA Synthesis kit (04896866001; Roche Diagnostics). PCR amplifications were quantified using SYBR Premix Ex Taq II (Tli RNaseH Plus; RR820A; Takara Biotechnology Co., Ltd., Dalian, China). Reactions were performed in a total volume of $20 \mu \mathrm{l}$, starting with an initial denaturation step at $95^{\circ} \mathrm{C}$ for $5 \mathrm{sec}$, followed by 40 cycles of denaturation at $95^{\circ} \mathrm{C}$ for $30 \mathrm{sec}$, annealing at $60^{\circ} \mathrm{C}$ for $34 \mathrm{sec}$ and an extension step at $72^{\circ} \mathrm{C}$ for $3 \mathrm{~min}$, followed by a 7 -min terminal extension at $72^{\circ} \mathrm{C}$. GAPDH gene expression was used as a reference in order to normalize the results using the $\Delta \Delta \mathrm{Cq}$ method (10). The following primers were used: GAPDH forward: 5'-TCATCAACGGGAAGCCCATC-3' and reverse: 5'-CTCGTGGTTCACACCCATCA-3'; ANP forward: 5'-ACCTGCTAGACCACCTGGAG-3' and reverse: 5'-CCTTGGCTGTTATCTTCGGTACCGG-3'; BNP forward: 5'-GAGGTCACTCCTATCCTCTGG-3' and reverse: 5'-GCC ATTTCCTCCGACTTTTCTC-3'; $\beta$-MHC forward: 5'-CCG AGTCCCAGGTCAACAA-3' and reverse: 5'-CTTCACGGG CACCCTTGGA-3'; CTGF forward: 5'-TGTGTGATGAGC CCAAGGAC-3' and reverse: 5'-AGTTGGCTCGCATCA TAGTTG-3'; collagen 1a forward: 5'-TGGTACATCAGCCCG AAC-3' and reverse: 5'-GTCAGCTGGATAGCGACA-3'; and TGF- $\beta_{1}$ forward: 5'-ATCCTGTCCAAACTAAGGCTCG-3' and reverse: 5'-ACCTCTTTAGCA AGTAGTCCGC-3'.

Western blot analysis. For western blot analysis, cardiac tissues were lysed in radioimmunoprecipitation assay lysis buffer. The amount of protein from each sample was calculated using a bicinchoninic acid assay kit (23227; Thermo Fisher Scientific, Inc.). Furthermore, the concentrations of the proteins were normalized prior to running any western blot experiments. Cardiac extracts were subjected to $10 \%$ sodium dodecyl sulfate-polyacrylamide gel electrophoresis, transferred to polyvinylidene difluoride (PVDF) membrane (Amersham; GE Healthcare Life Sciences, Chalfont, UK), and blocked in $7 \%$ milk. The membrane was washed with Tris-buffered saline Tween-20 for $15 \mathrm{~min}$ and then incubated overnight at $4^{\circ} \mathrm{C}$ with the indicated primary antibodies. These were the following: GAPDH $(1: 1,000)$, ANP (1:200), BNP (1:200), $\beta$-MHC (1:200), CTGF (1:200), Collagen $1 \alpha$ $(1: 200)$ and TGF- $\beta 1$ (1:1,000). Following incubation with the secondary immunoglobulin $\mathrm{G}$ antibodies (1:1,000; alkaline phosphatase) for $1 \mathrm{~h}$ at room temperature in $3 \%$ milk. These were the following antibodies: rabbit antibody (IRDye800CW, 926-32211, LI-COR Biosciences, NE, USA) for GAPDH, ANP, CTGF and TGF- $\beta 1$; mouse antibody (IRDye800CW, 926-32210, LI-COR Biosciences, NE, USA) for $\beta$-MHC and collagen $1 \alpha$; goat antibody for BNP (IRDye800CW, 926-32232, LI-COR Biosciences, NE, USA). Quantification of western blots was performed using an Odyssey infrared imaging system (Li-Cor Biosciences, Lincoln, NE, USA). The GAPDH protein was used to normalize specific protein expression levels for the total cardiac lysate proteins on the same PVDF membranes.

Statistical analysis. Graphs were generated with GraphPad Prism 6 (GraphPad Software Inc., La Jolla, CA, USA), and the data in the figures are expressed as the mean \pm standard error of the mean. The significance of differences between experimental and control groups was evaluated using one-way analysis of variance with Student Newman-Keuls test. Comparison of survival was performed using Kaplan-Meier 
Table I. Echocardiograhic parameters of C57BL/6 mice at baseline.

\begin{tabular}{|c|c|c|c|c|c|c|}
\hline \multirow[b]{2}{*}{ Parameter } & \multicolumn{2}{|c|}{ Sham } & \multicolumn{4}{|c|}{$\mathrm{AB}$} \\
\hline & Saline & Biso & Saline & L-Biso & M-Biso & H-Bsio \\
\hline Number & 12 & 12 & 14 & 16 & 16 & 16 \\
\hline BW (g) & $24.97 \pm 0.24$ & $24.87 \pm 0.17$ & $24.91 \pm 0.18$ & $25.16 \pm 0.13$ & $25.50 \pm 0.20$ & $25.10 \pm 0.24$ \\
\hline HR (bpm) & $495.50 \pm 4.80$ & $502.45 \pm 4.24$ & $508.00 \pm 5.43$ & $508.94 \pm 6.20$ & $505.44 \pm 6.94$ & $506.81 \pm 5.56$ \\
\hline LVESD (mm) & $2.84 \pm 0.09$ & $3.05 \pm 0.11$ & $2.78 \pm 0.12$ & $2.81 \pm 0.06$ & $2.91 \pm 0.07$ & $2.99 \pm 0.07$ \\
\hline LVEDD (mm) & $4.07 \pm 0.10$ & $4.34 \pm 0.11$ & $4.30 \pm 0.11$ & $4.14 \pm 0.06$ & $4.17 \pm 0.08$ & $4.30 \pm 0.10$ \\
\hline IVSD (mm) & $0.46 \pm 0.02$ & $0.48 \pm 0.01$ & $0.49 \pm 0.01$ & $0.49 \pm 0.01$ & $0.47 \pm 0.02$ & $0.50 \pm 0.02$ \\
\hline LVPWD (mm) & $0.70 \pm 0.02$ & $0.69 \pm 0.02$ & $0.71 \pm 0.02$ & $0.70 \pm 0.01$ & $0.73 \pm 0.01$ & $0.70 \pm 0.02$ \\
\hline FS $(\%)$ & $30.40 \pm 0.83$ & $29.73 \pm 0.91$ & $30.62 \pm 0.80$ & $31.13 \pm 0.76$ & $30.00 \pm 0.78$ & $30.56 \pm 0.86$ \\
\hline $\mathrm{EF}(\%)$ & $64.60 \pm 1.26$ & $63.45 \pm 1.38$ & $64.54 \pm 1.04$ & $63.50 \pm 0.93$ & $64.25 \pm 1.21$ & $64.31 \pm 0.83$ \\
\hline
\end{tabular}

Table II. Echocardiographic parameters of C57BL/6 mice at 8 weeks after sham or AB surgery.

\begin{tabular}{|c|c|c|c|c|c|c|}
\hline \multirow[b]{2}{*}{ Parameter } & \multicolumn{2}{|c|}{ Sham } & \multicolumn{4}{|c|}{$\mathrm{AB}$} \\
\hline & Saline & Biso & Saline & L-Biso & M-Biso & H-Bsio \\
\hline Number & 5 & 6 & 4 & 6 & 6 & 6 \\
\hline BW (g) & $31.10 \pm 0.68$ & $27.11 \pm 0.47$ & $26.56 \pm 0.68^{a}$ & $27.53 \pm 0.64$ & $28.28 \pm 0.59$ & $26.77 \pm 1.15$ \\
\hline HR (bpm) & $550.80 \pm 21.31$ & $537.67 \pm 21.80$ & $482 \pm 21.00$ & $548.83 \pm 17.51$ & $544.17 \pm 21.72$ & $533.00 \pm 24.89$ \\
\hline LVESD (mm) & $3.02 \pm 0.17$ & $2.98 \pm 0.11$ & $4.80 \pm 0.07^{\mathrm{a}}$ & $3.52 \pm 0.17^{b}$ & $4.32 \pm 0.17$ & $4.55 \pm 0.15$ \\
\hline LVEDD (mm) & $4.32 \pm 0.14$ & $4.28 \pm 0.08$ & $6.13 \pm 0.13^{\mathrm{a}}$ & $4.87 \pm 0.28^{b}$ & $5.52 \pm 0.19$ & $5.83 \pm 0.14$ \\
\hline IVSD (mm) & $0.52 \pm 0.03$ & $0.47 \pm 0.02$ & $0.70 \pm 0.01^{\mathrm{a}}$ & $0.65 \pm 0.03^{b}$ & $0.55 \pm 0.03$ & $0.54 \pm 0.03$ \\
\hline LVPWD (mm) & $0.69 \pm 0.03$ & $0.65 \pm 0.03$ & $0.83 \pm 0.02^{\mathrm{a}}$ & $0.76 \pm 0.03$ & $0.71 \pm 0.04$ & $0.68 \pm 0.03$ \\
\hline $\mathrm{FS}(\%)$ & $30.60 \pm 0.60$ & $30.17 \pm 1.11$ & $22.50 \pm 0.96^{\mathrm{a}}$ & $30.00 \pm 0.77$ & $26.00 \pm 1.15^{\mathrm{c}}$ & $22.00 \pm 1.03^{\mathrm{d}}$ \\
\hline $\mathrm{EF}(\%)$ & $64.40 \pm 1.89$ & $63.00 \pm 2.14$ & $48.25 \pm 1.60^{\mathrm{a}}$ & $62.67 \pm 1.94$ & $56.17 \pm 2.27^{c}$ & $50.17 \pm 1.89^{d}$ \\
\hline
\end{tabular}

analysis. $\mathrm{P}<0.05$ was considered to indicate a statistically significant difference.

\section{Results}

Long-term administration of bisoprolol reveals substantial benefits. Initially, the potential existence of a time-response association for various doses of bisoprolol in the enhancement of cardiac functions was investigated. Echocardiographic parameters, including LVEDD, LVESD, IVSD, LVPWD, FS and $\mathrm{EF}$, which have commonly been used in the clinic for estimating cardiac functions, were measured at 4 and 8 weeks after sham or AB surgery. There was no clear phenotypic difference among all of the groups at baseline, as assessed by echocardiography (Table I), or at 4 weeks (Fig. 1). The latter observation may be attributed to the compensatory role of the heart. The long-term administration of bisoprolol to mice until 8 weeks after surgery (Table II) revealed statistically significant differences among the groups, in contrast with administration for 4 weeks (Fig. 1). Altogether, these data indicate that the role of bisoprolol in the attenuation of cardiac function is dependent upon the time period for which it is used, with long-term administration of bisoprolol demonstrating a greater benefit than short-term use.

Diversities between middle-and high-dose bisoprolol are not remarkable in the attenuation of cardiac hypertrophy induced by pressure overload. To investigate whether there is some 
A

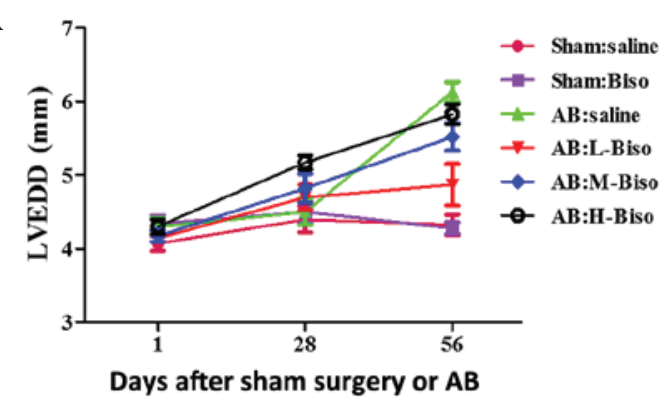

C

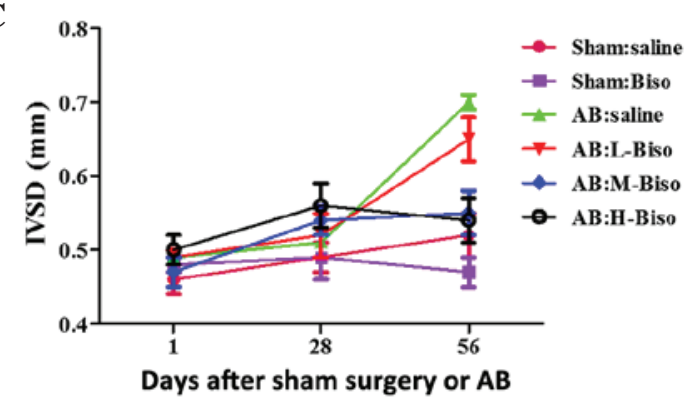

$\mathbf{E}$

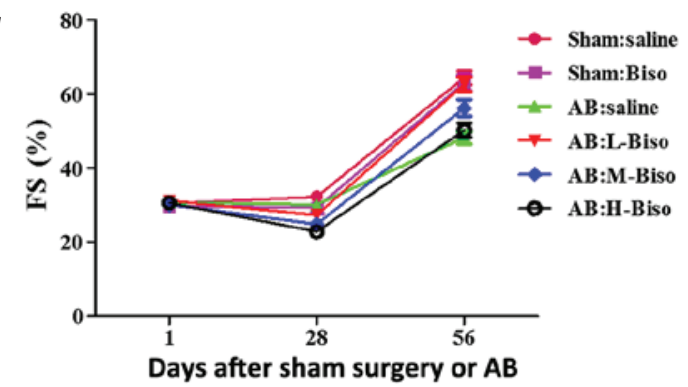

B

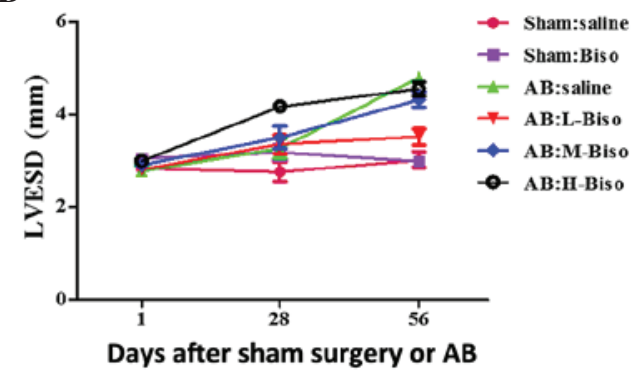

D

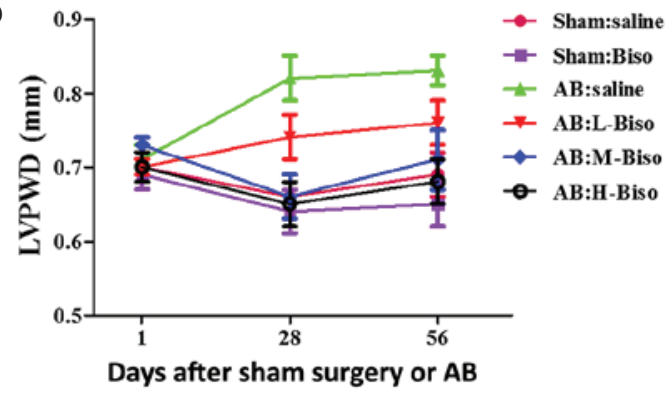

F

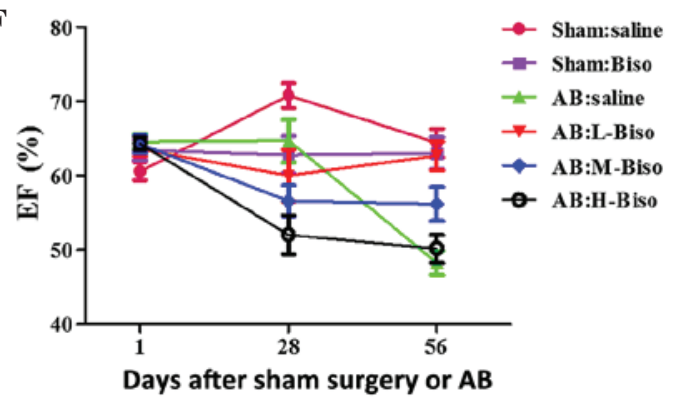

Figure 1. Echocardiographic parameters at different time-points. (A) Left ventricular end-diastolic diameter (LVEDD), (B) left ventricular end-systolic diameter (LVESD), (C) left ventricular septum diastolic (IVSD), (D) left ventricular posterior wall diameter (LVPWD), (E) fractional shortening (FS) and (F) ejection fraction (EF). Data are presented as mean \pm standard error of the mean (n=12-16 in each group) and were analyzed with 2 -way repeated-measures analysis of variance. Bonferroni correction was applied for multiple comparisons. (A-F) $\mathrm{P}<0.01$ for $\mathrm{H}$-Biso and M-Biso vs. the other four groups at 8 weeks (56 days), but no significant difference between the M-Biso and H-Biso groups. AB, aortic banding; Biso, bisoprolol; L, low-dose; M, middle-dose; H, high-dose.

diversity among the different doses of bisoprolol in attenuating the cardiac hypertrophy induced by pressure overload, the $\mathrm{AB}$ model was used to induce hypertrophy. The degree to which hypertrophy was affected by different doses of bisoprolol was assessed by echocardiographic, histomorphological and molecular analysis. After 8 weeks, echocardiographic and $\mathrm{P}-\mathrm{V}$ loop analyses were performed in order to observe the chamber diameter, wall thickness and function of the left ventricle. Results demonstrated that there were no significant changes in the two groups mice that underwent sham surgery, whereas there were marked diversities among the four groups that underwent $\mathrm{AB}$ surgery. However, there was no statistically significant difference between the middle- and high-dose bisoprolol groups (Fig. 2A). In the $\mathrm{AB}$ groups, mice that received intragastric administration of saline or low-dose bisoprolol exhibited deteriorated cardiac hypertrophy and dysfunction compared with the mice that were treated with middle- or high-dose bisoprolol, as measured by echocardiographic parameters such as LVEDD, LVESD, LVPWD,
FS and EF\% after 8 weeks of AB (Fig. 2B). A more detailed examination of cardiac function was performed using invasive pressure-volume analysis. At 8 weeks after $\mathrm{AB}$, distinct phenotypes were observed among the groups in terms of the progression of cardiac dysfunction measured by end-systolic and end-diastolic pressure, dp/dt max and dp/dt min (Fig. 2C). The mice intragastrically treated with saline following $A B$ demonstrated an increase in heart size and dilatation of ventricular chambers as compared with the sham group and other AB groups (Fig. 3A). Furthermore, not only were the whole hearts much smaller after bisoprolol treatment compared with those of saline-treated $\mathrm{AB}$ mice but also the $\mathrm{HW} / \mathrm{BW}$, $\mathrm{LW} / \mathrm{BW}$, and HW/TL ratios were significantly decreased. However, the diversities between middle- and high-dose were not remarkable at 8 weeks after surgery (Fig. 3B). Observation of the hearts, and the H\&E and WGA-FITC staining results were consistent with the echocardiographic results (Fig. 3A).

In order to explore whether the different doses of bisoprolol correspond with changes in the protein levels and 
A

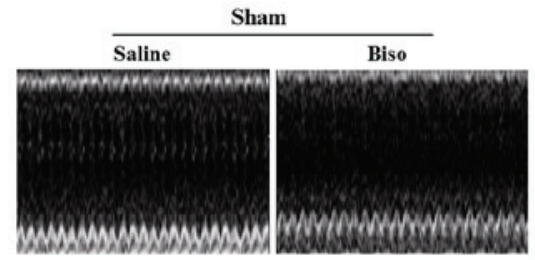

B
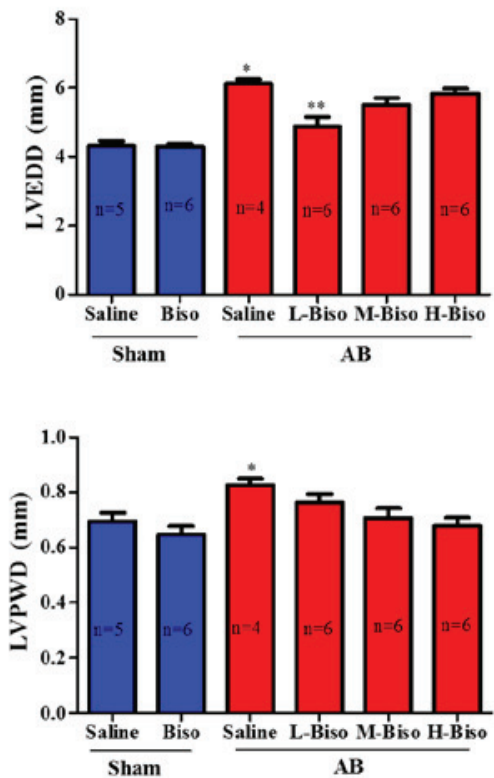

AB
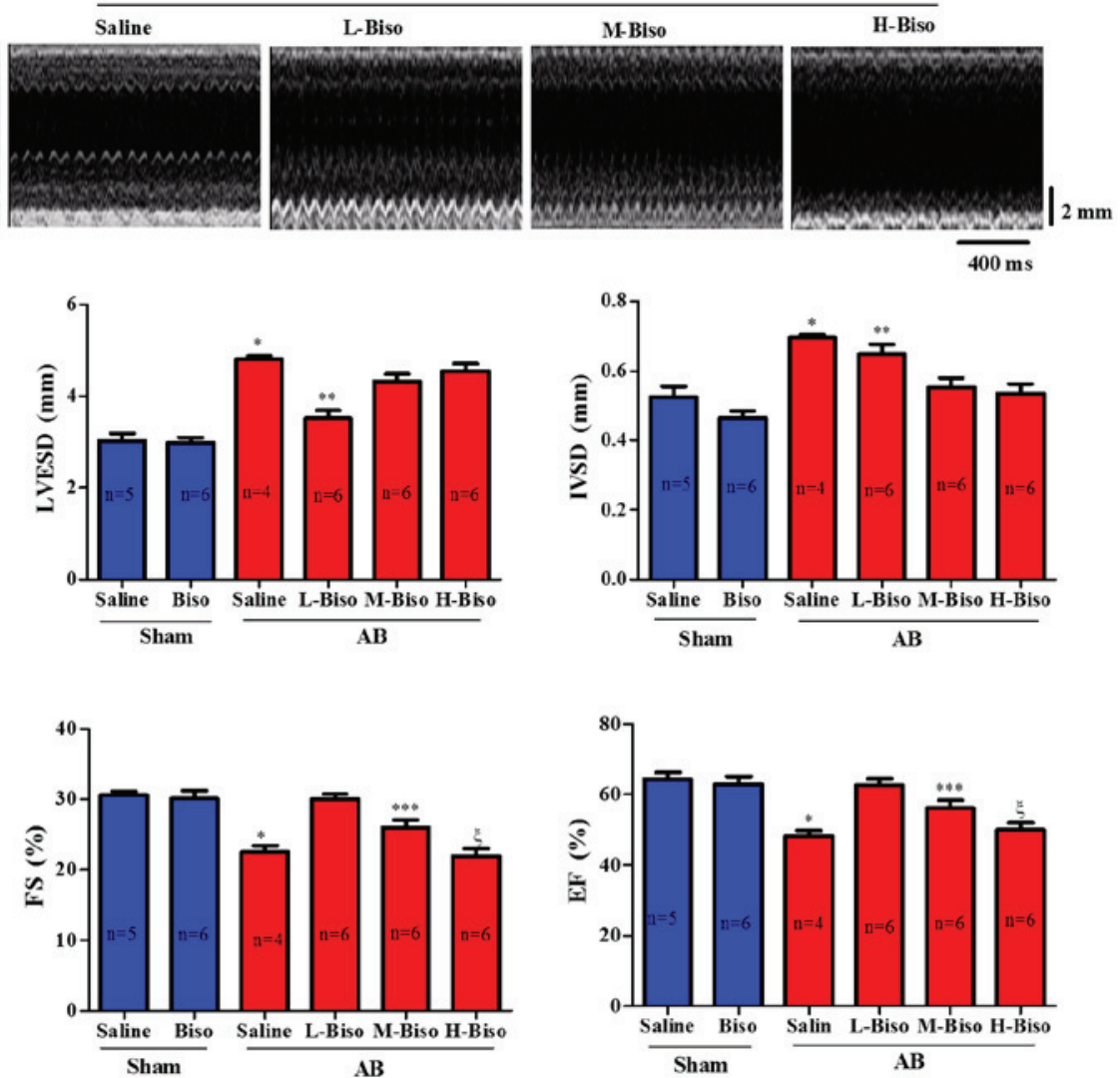

C
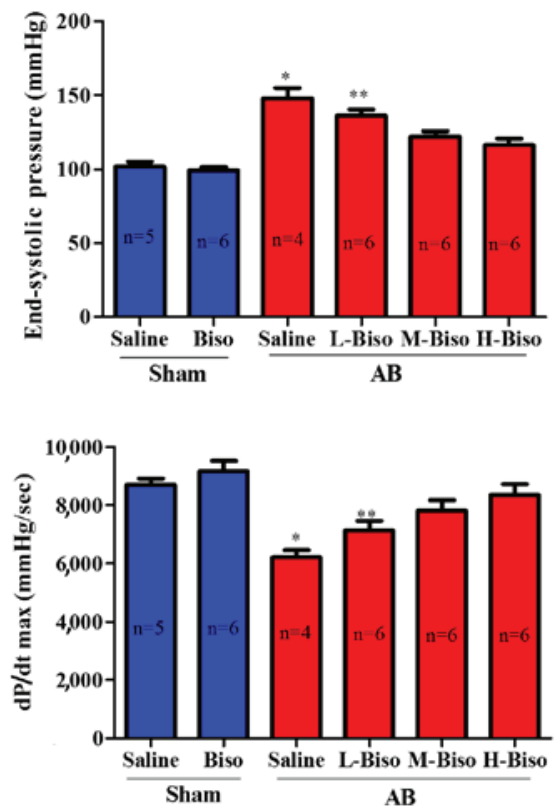
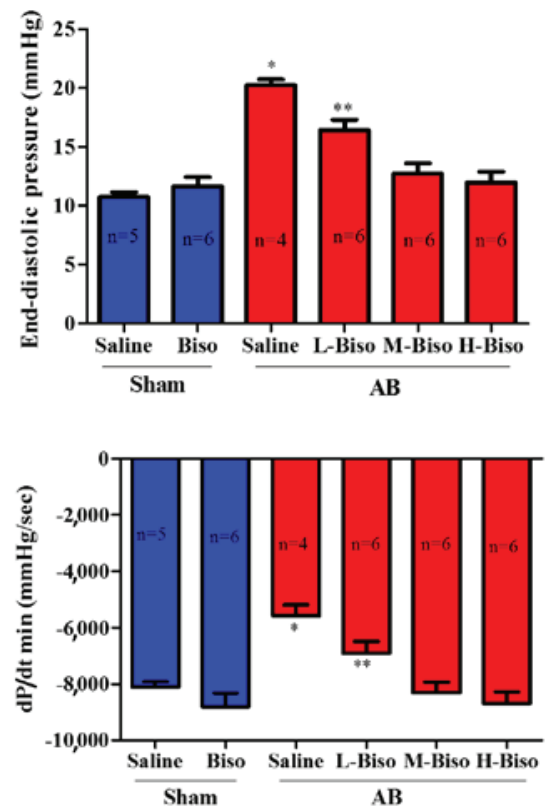

Figure 2. Bisoprolol increases adverse pressure overload-induced ventricular remodeling. (A) Representative serial M-mode echocardiography in conscious mice from the six experimental groups at 8 weeks after sham or AB surgery. (B) Quantitative analysis of echocardiographic parameters. (C) Summary of hemodynamic data on systolic function and diastolic function. All values are the mean \pm standard error of the mean ( $\mathrm{n}=4-6$ per group). ${ }^{*} \mathrm{P}<0.05 \mathrm{vs.} \mathrm{all} \mathrm{other}$ groups, ${ }^{* *} \mathrm{P}<0.05$ vs. M-Biso $\mathrm{AB}$ and $\mathrm{H}$-Biso $\mathrm{AB},{ }^{* * *} \mathrm{P}<0.05$ vs. H-Biso $\mathrm{AB},{ }^{5} \mathrm{P}<0.05$ vs. L-Biso $\mathrm{AB}$ and $\mathrm{M}-\mathrm{Biso} \mathrm{AB}$. AB, aortic banding; Biso, bisoprolol; L, low-dose; M, middle-dose; H, high-dose; LVEDD, left ventricular end-diastolic diameter; LVESD, left-ventricular end-systolic diameter; IVSD, left ventricular septum diastolic; LVPWD, left ventricular posterior wall diameter; FS, fractional shortening; EF, ejection fraction; dp/dt, left ventricular contractility.

mRNA expression of markers of cardiac hypertrophy, western blot analysis and qPCR analysis of fetal genes, including ANP, BNP and $\beta$-MHC were performed. The results demonstrated a significant reduction of the mRNA expression and protein levels of ANP, BNP and $\beta$-MHC from those in the saline-treated
AB group when the animals were treated with bisoprolol (Fig. 3C and D). In addition, the results indicated that the middle- and high-dose of bisoprolol inhibited the protein and mRNA expression levels of the cardiac hypertrophy markers $\mathrm{ANP}, \mathrm{BNP}$, and $\beta$-MHC the most notably; however, there 
A
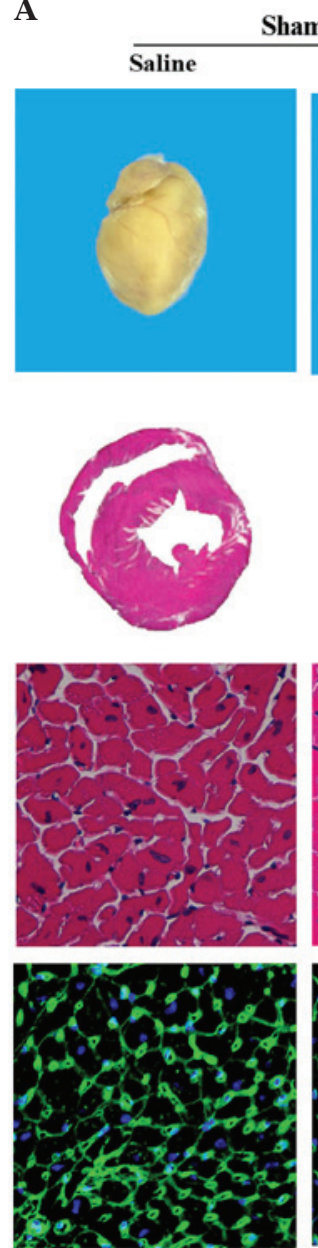

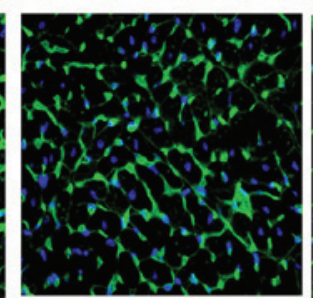

Biso
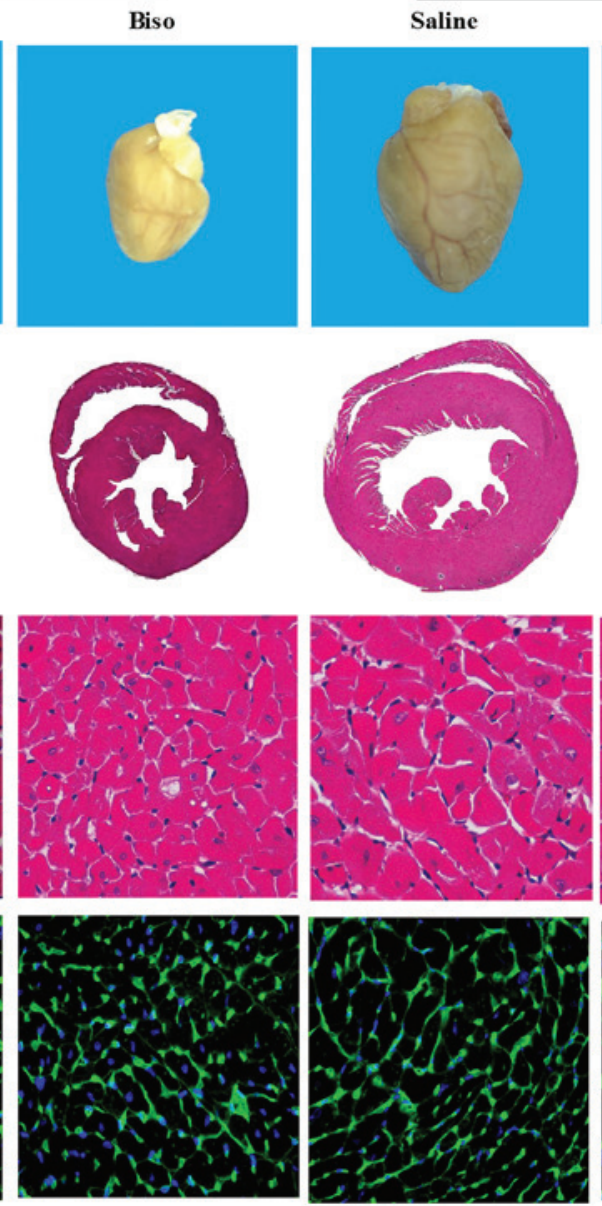

AB
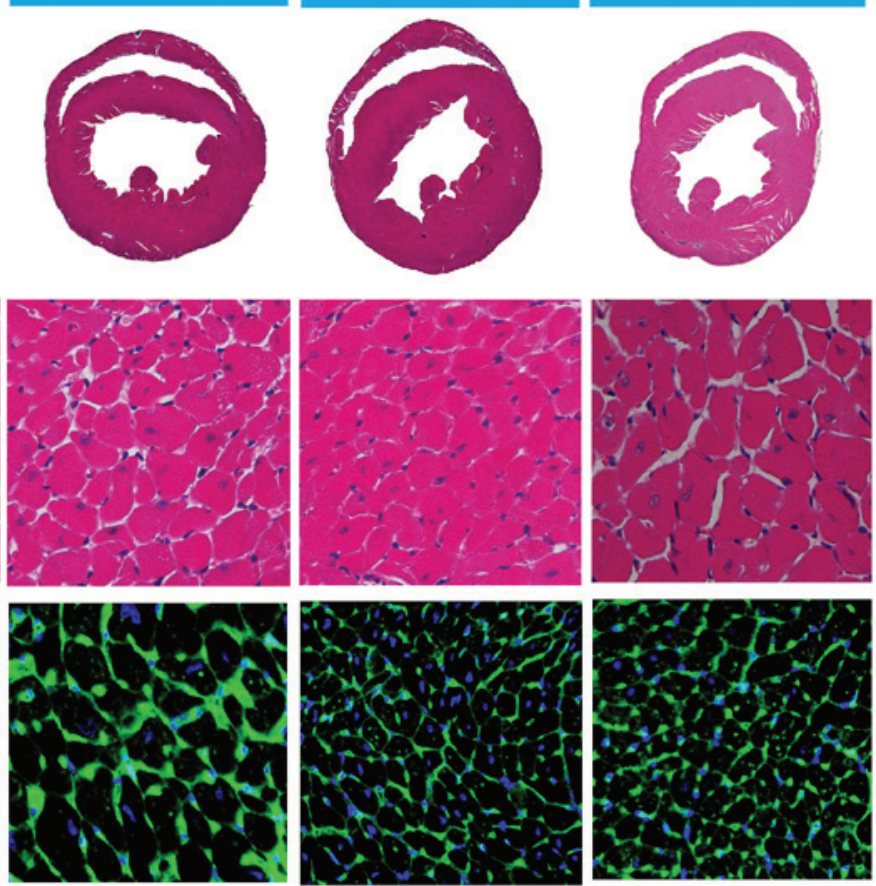
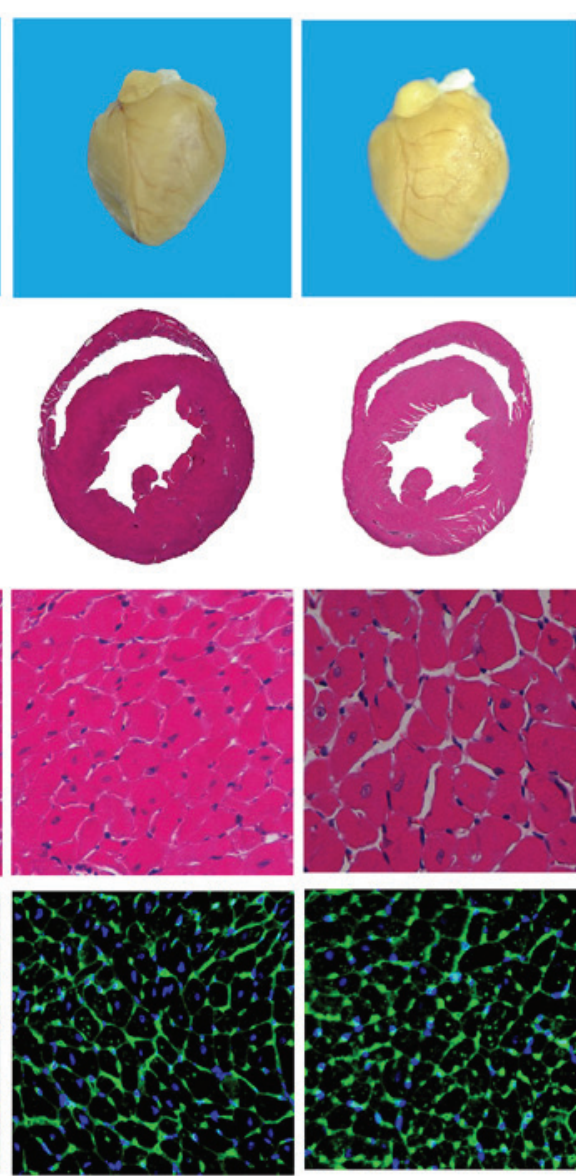

$\mathbf{B}$
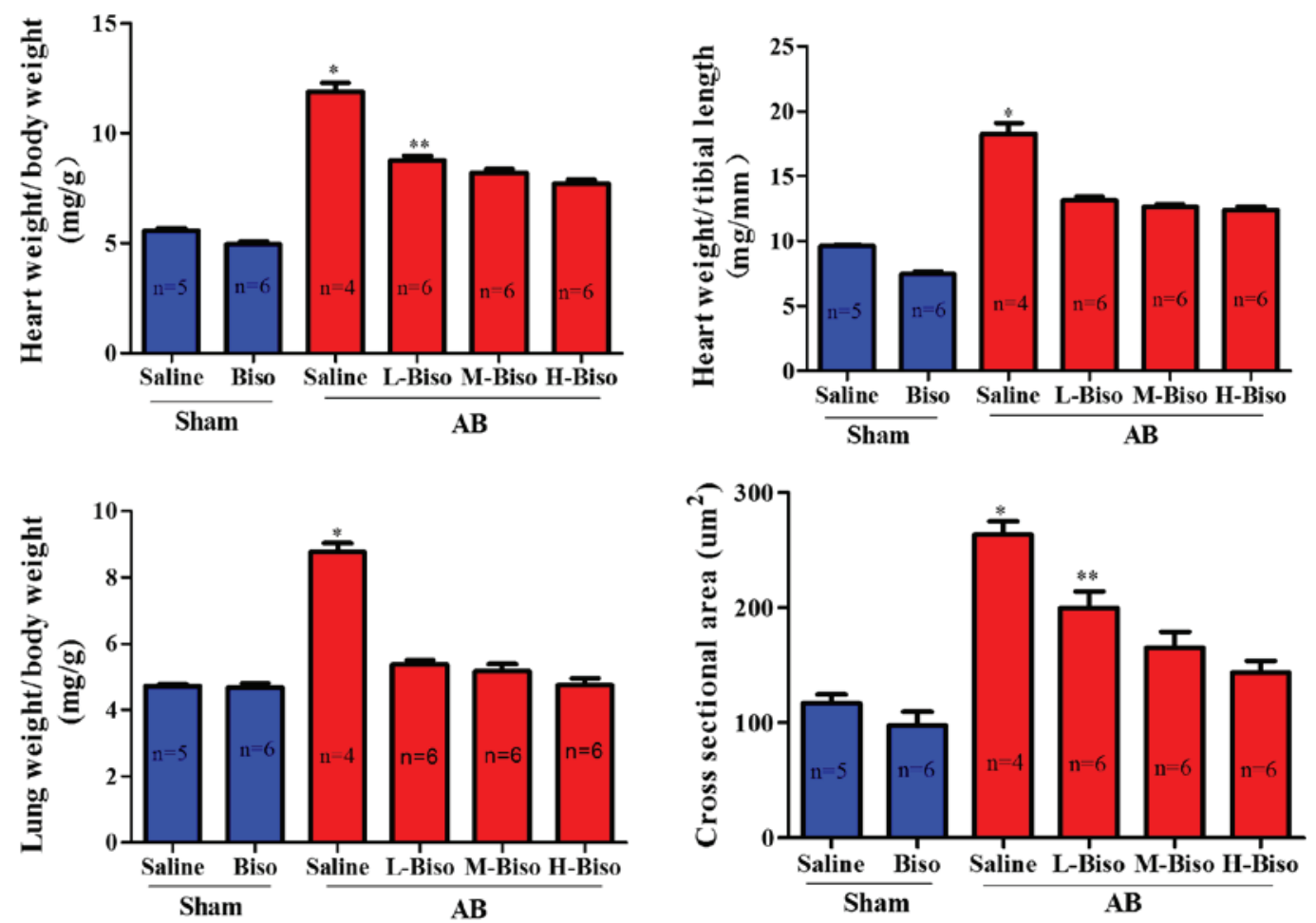

Figure 3. Bisoprolol attenuated cardiac hypertrophy induced by pressure overload. (A) Histological changes. Upper images, gross observation of hearts; middle images, representative images of hematoxylin and eosin staining of whole hearts (magnification, x1) and sections (magnification, $\mathrm{x} 40$ ); lower images, wheat germ agglutinin-fluorescein isothiocyanate staining (magnification, $\mathrm{x} 40$ ) at 8 weeks post-aortic banding (AB) surgery. (B) Graphical results of HW/BW ratio, LW/BW ratio, $\mathrm{HW} / \mathrm{TL}$ ratio, and myocyte cross-sectional areas $\left(\mathrm{n}=100\right.$ cells per group) at 8 weeks post- $\mathrm{AB}$ surgery ( $\mathrm{n}=6$ ). ${ }^{*} \mathrm{P}<0.05$ vs. the other five groups, ${ }^{* *} \mathrm{P}<0.05$ vs. M-Biso AB and H-Biso AB groups. Biso, bisoprolol; L, low-dose; M, middle-dose; H, high-dose; HW, heart weight; BW, body weight; TL, tibial length. 
C

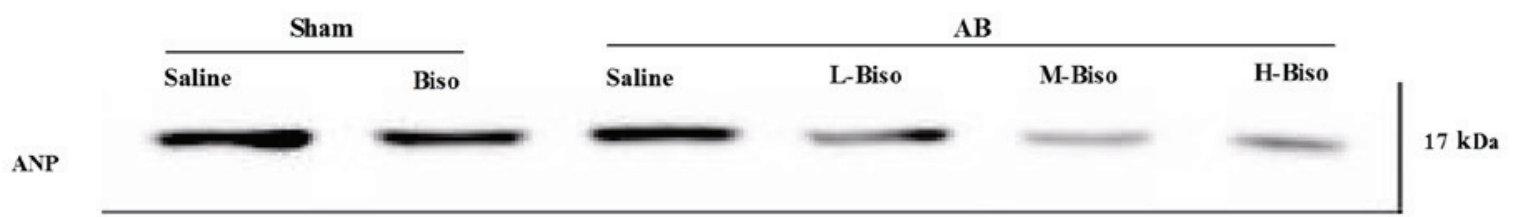

BNP

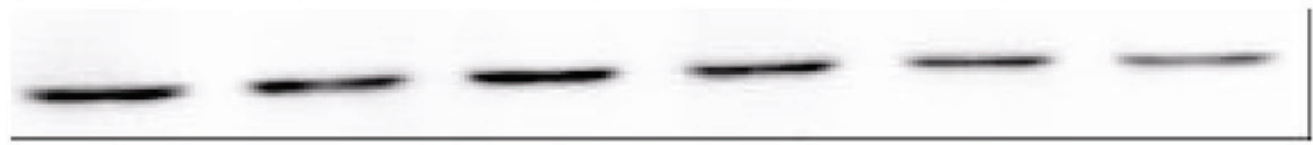

$25 \mathrm{kDa}$

B -MHC

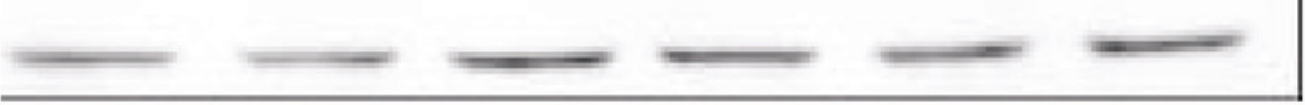

$223 \mathrm{kDa}$

GAPDH
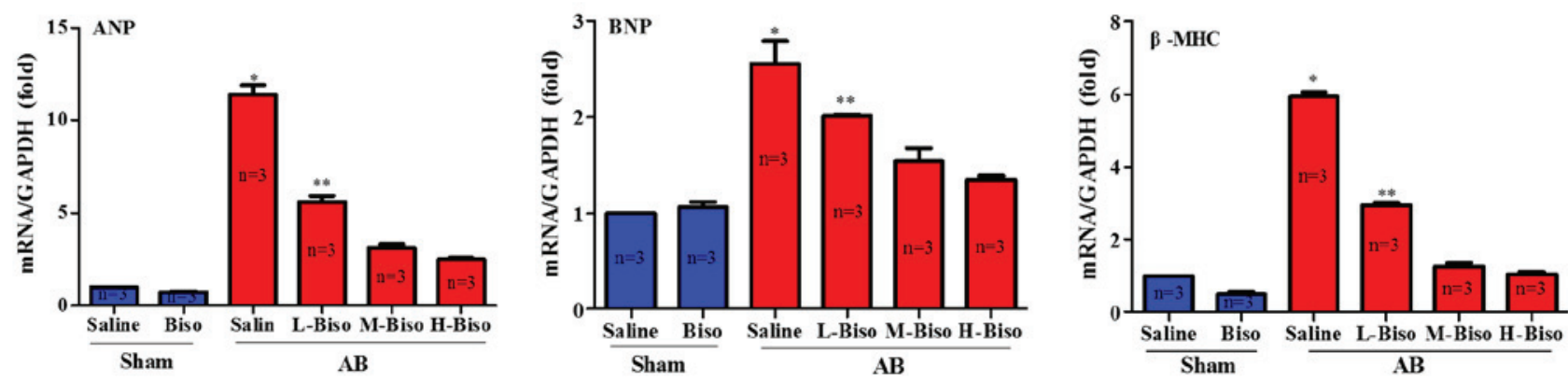

Figure 3. Continued. (C) Representative western blots of atrial natriuretic peptide (ANP), brain natriuretic peptide (BNP) and $\beta$-major histocompatibility complex (MHC) at 8 weeks post-sham and aortic banding (AB) surgery. (D) Quantitative polymerase chain reaction analysis of ANP, BNP and $\beta$-MHC at 8 weeks post-sham and $\mathrm{AB}$ surgery ( $\mathrm{n}=3$ per group). Values represent the mean \pm standard error of the mean. " $\mathrm{P}<0.05$ vs. all other groups. ${ }^{* *} \mathrm{P}<0.05$ vs. $\mathrm{M}$-Biso $\mathrm{AB}$ and $\mathrm{H}$-Biso AB. Biso, bisoprolol; L, low-dose; M, middle-dose; H, high-dose; GAPDH, glyceraldehyde 3-phosphate dehydrogenase.

were no statistically significant differences between these two groups (Fig. 3C and D). Altogether, the aforementioned data clearly indicate that there is no noteworthy difference between the high-dose, i.e., the target-dose, and middle-dose bisoprolol in the attenuation of cardiac hypertrophy induced by pressure overload.

Amelioration of the degree of cardiac fibrosis is not evidently different between middle- and high-dose bisoprolol. Pathological cardiac hypertrophy correlates with increased fibrosis in the myocardium (11). Fibrosis is a typical feature of pathological cardiac hypertrophy, characterized by the accumulation of collagen. To investigate the extent by which different doses of bisoprolol inhibit cardiac fibrosis, paraffin-embedded slides were stained with PSR at 8 weeks after AB surgery, and the staining was quantitatively analyzed from interstitial and perivascular regions of the left ventricles. Also, the extent of fibrosis was investigated by assessing the protein and mRNA expression levels of fibrotic genes, including $T g f-\beta_{1}$ (encoding TGF- $\beta_{1}$ ), Colla (encoding collagen 1a) and $C \operatorname{tg} f$ (encoding CTGF) $(12,13)$. The results revealed that long-term treatment of mice with bisoprolol following $\mathrm{AB}$ surgery reduced interstitial and perivascular cardiac fibrosis (Fig. 4A). Furthermore, a marked attenuating effect of middle- and high-doses of bisoprolol on cardiac fibrosis was identified by quantitative analysis of collagen volume in the interstitial and perivascular regions; however, no statistically significant difference was observed between these two groups (Fig. 4B and C). Reduced fibrosis in the mice treated with middle- and high-dose bisoprolol may represent decreased collagen synthesis or increased collagen degradation in response to tissue damage. Therefore, the synthesis of collagen was assessed by examining the protein and mRNA expression levels of fibrotic markers CTGF, collagen 1a, and TGF- $\beta_{1}$, all of which have a function in the proliferation of cardiac fibroblasts and the biosynthesis of extracellular matrix (ECM) proteins. The data revealed that the mRNA and protein expression levels of CTGF, Collagen 1a, and TGF- $\beta_{1}$ were significantly lower in the middle- and high-dose bisoprolol-treated mice than in the saline and low-dose bisoprolol-treated mice at 8 weeks after AB surgery. However, there were no statistically significant differences between the middle- and high-dose bisoprolol groups (Fig. 4D and E). These data demonstrate that middleand high-dose bisoprolol have comparable effects in the attenuation of cardiac fibrosis induced by pressure overload.

Survival following $A B$. Treatment with middle- or high-dose bisoprolol therapy was associated with a significantly improved survival rate at 8 weeks after $\mathrm{AB}$ compared with saline therapy $(\mathrm{P}<0.05$ vs. saline). However, no statistically significant difference in survival was observed between the middle- and high-dose bisoprolol groups (Fig. 5). 
A

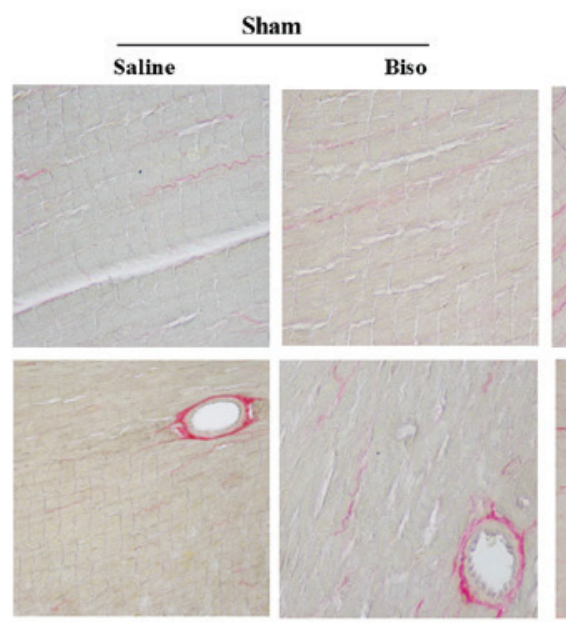

B

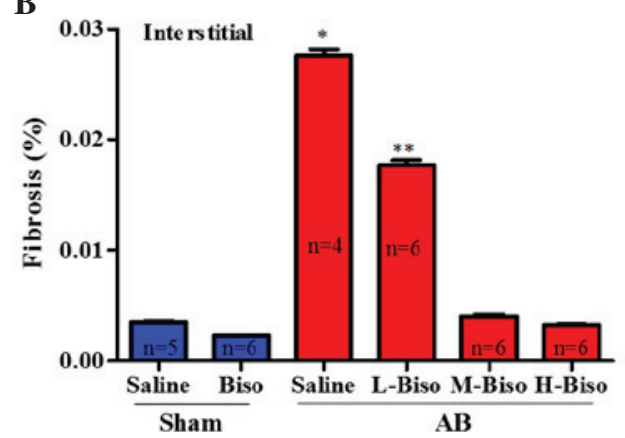

D

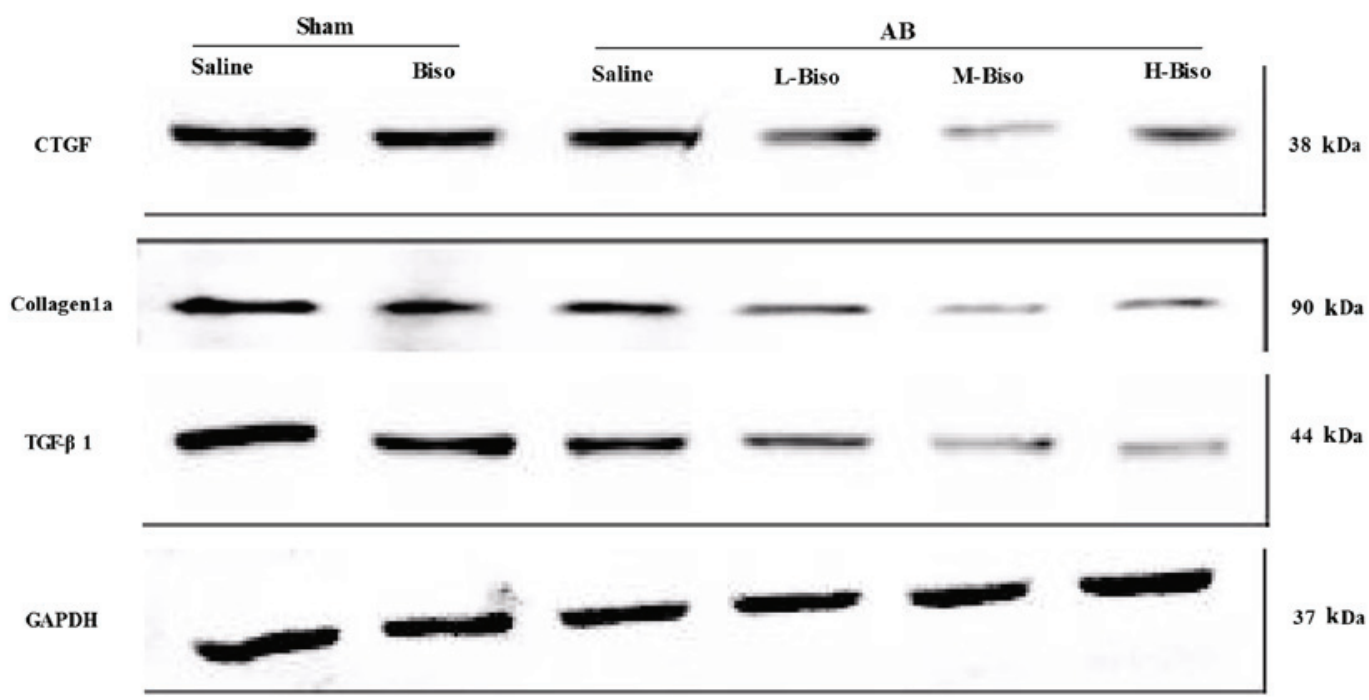

C

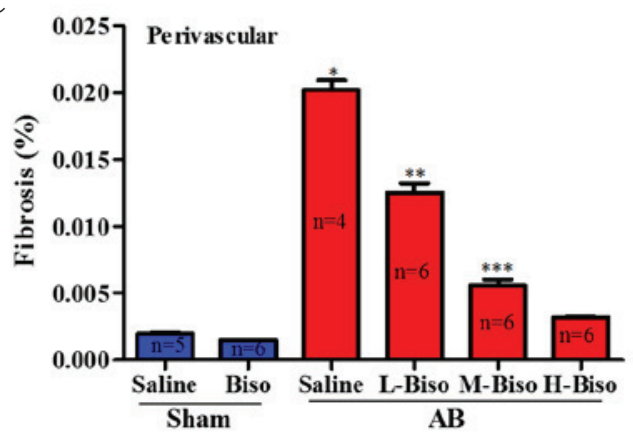

$\mathbf{E}$

M-Biso H-Biso
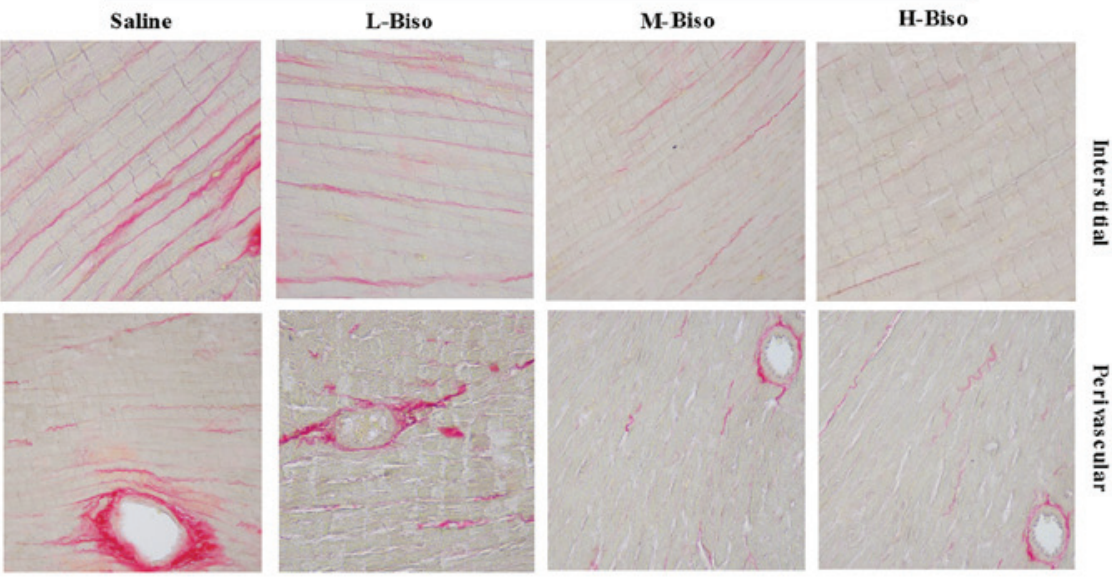

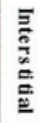



\section{(1)

(1)
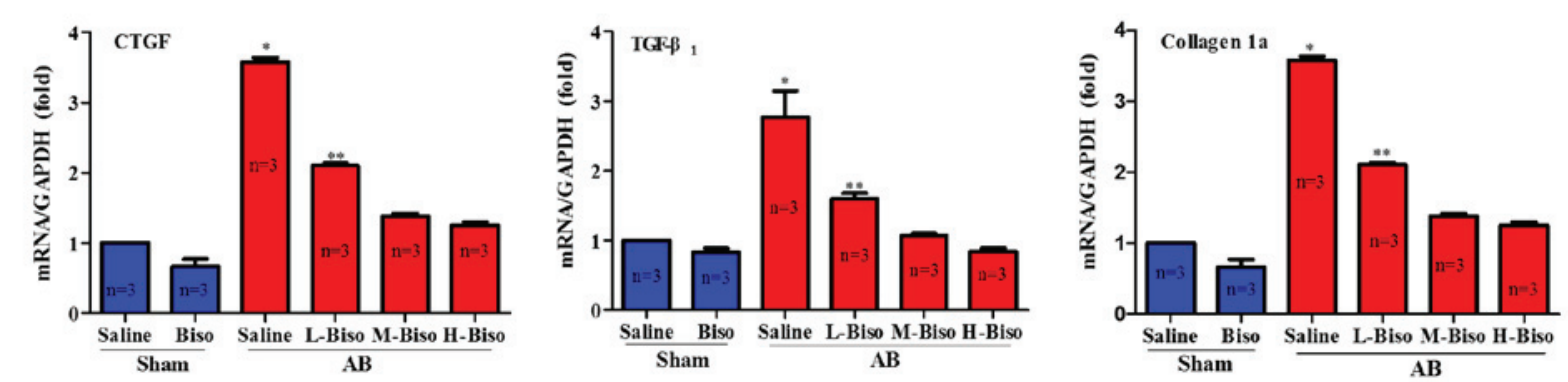

Figure 4. Bisoprolol attenuates cardiac fibrosis in response to pressure overload in vivo. (A) Picrosirius red staining of interstitial (top) and perivascular (bottom) regions of left ventricles of C57BL/6J mice following treatment of saline or bisoprolol at 8 weeks after sham or aortic banding (AB) surgery. Quantification of collagen volume fraction from (B) interstitial and (C) perivascular regions ( $n=4-6$ per group). (D) Representative western blots of connective tissue growth factor (CTGF), tissue growth factor (TGF)- $\beta 1$ and collagen 1a at 8 weeks after sham or AB surgery. (E) Quantitative mRNA expression levels of CTGF, TGF- $\beta 1$ and collagen 1a in the groups ( $\mathrm{n}=3$ per group). Values represent the mean \pm standard error of the mean. $\mathrm{P}<0.05$ vs. all other groups. ${ }^{* *} \mathrm{P}<0.05$ vs. M-Biso and $\mathrm{H}-\mathrm{Biso}$ AB groups; ${ }^{* * *} \mathrm{P}<0.05$ vs. H-Biso AB groups. Biso, bisoprolol; L, low-dose; $\mathrm{M}$, middle-dose; H, high-dose; GAPDH, glyceraldehyde 3-phosphate dehydrogenase. 


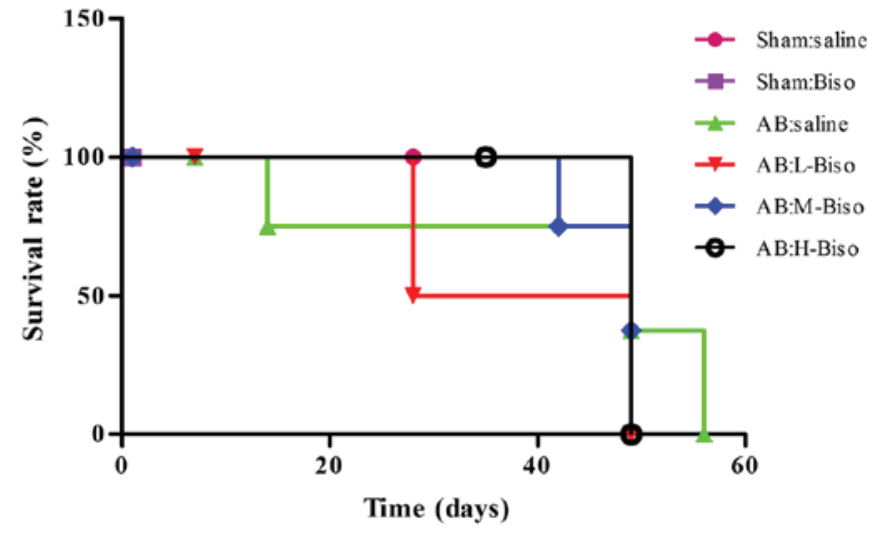

Figure 5. Kaplan-Meier survival curves for mice after aortic banding (AB) with different treatments. Survival rates for mice after AB or sham surgery and treatment with saline, low-dose, middle-dose and high-dose bisoprolol at different time-points are shown. Percentages of surviving mice are plotted. Biso, bisoprolol; L, low-dose; M, middle-dose; H, high-dose.

\section{Discussion}

Hemodynamic overload and ischemic or oxidative stress promote adverse cardiac remodeling, which is a leading cause of worsening heart failure (14). The pathophysiological conditions of heart failure are associated with adrenergic stimulation and catecholamine release, resulting in adrenoceptor (AR) activation on different cell types within the myocardium. Among these, $\beta_{1}$-ARs are classically considered to mediate short-term positive effects on all aspects of myocardial contractility; however, long-term stimulation produces adverse effects on myocardial remodeling (15). The aim of the present study was to clarify the underlying benefits of bisoprolol in the attenuation of the ventricular remodeling induced by pressure overload with the use of different doses in mice.

When the heart undergoes pressure or volume overload, myocardial hypertrophy begins as an adaptive response. This is often observed in valve disease, arterial hypertension or following myocardial infarction. When cardiomyocyte hypertrophy occurs, an increase in cell size and protein content is observed, as well as a repeated expression of a fetal gene programme that includes ANP, BNP and $\beta$-MHC. Furthermore, the expression of immediate early genes is also observed (16). When overload is prolonged, the initially compensatory hypertrophic response may become maladaptive, which may result in chronic heart failure $(17,18)$.

Previous studies have revealed that the $\beta_{1}$-AR subtype is not only the major mediator of pathological hypertrophy, but also is associated with a notable increase in interstitial fibrosis and heart failure $(19,20)$. This is also supported by the beneficial effect of $\beta_{1}$-AR blockade in clinical heart failure. $\beta$-blockers are thought to function by reducing the sympathetic activity and the workload of the heart, and by exerting beneficial effects on the ventricular remodeling process $(21,22)$. According to European and American guidelines, the use of $\beta$-blockers in symptomatic patients with heart failure has a class $1 \mathrm{~A}$ recommendation $(23,24)$. Nonetheless, uptake of therapy in clinical practice remains suboptimum, with patients who are at greatest risk of mortality being the least likely to receive evidence-based therapy (25). There have also been concerns with regard to the treatment efficacy in several groups, notably patients with atrial fibrillation, coronary artery bypass graft $(26,27)$ and cardiac pacemaker surgeries $(28)$, women, and elderly individuals (29).

Although $\beta$-blockers have been widely used in the treatment of endoscopic sinus surgery (30), hypertension, coronary artery disease, dilated cardiomyopathy and heart failure $(27,31)$, the clinical efficacy among different $\beta$-blockers does not appear to be equivalent (32). In the present study, different doses of a highly selective $\beta_{1}$-AR-blocking antagonist, bisoprolol, not metoprolol (which induces fibrosis and cardiac dysfunction) (33) was used in order to improve cardiac function in the AB model. The assessment of echocardiographic results in the present study demonstrated a greater improvement in cardiac function after 8 weeks of treatment with bisoprolol compared with that in mice treated with bisoprolol after $\mathrm{AB}$ or sham surgery at 4 weeks. No statistically significant difference was observed between the middle- and high-dose bisoprolol treatment groups (Fig. 1). These outcomes highlight that the attenuating effect of bisoprolol on ventricular cardiac hypertrophy induced by pressure overload occurs in a time-dependent manner. In subsequent experiments, the aim was to further elucidate this phenomenon in mice treated with different doses of bisoprolol following AB or sham surgery by investigating changes of the hearts using echocardiographic imaging (Fig. 2A and B), hemodynamic analysis (Fig. 2C) and histomorphology (Fig. 3A and B) after 8 weeks. The experimental results confirmed that the middle- and high-doses were important in enhancing cardiac function following $\mathrm{AB}$ surgery; however, no statistically significant difference was observed between them. The aforementioned outcomes were also confirmed by exploring the protein and mRNA expression levels of markers of cardiac hypertrophy, namely ANP, BNP and $\beta$-MHC (Fig. 3C and D). Altogether, these data clearly indicate that there is a time-dependent effect of high- and middle-dose bisoprolol treatment in the attenuation of cardiac hypertrophy induced by pressure overload, but no notable difference between these two doses.

Cardiac fibrosis is an important hallmark of maladaptive hypertrophy. Increased fibrosis decreases myocardial compliance, impairs diastolic relaxation and causes cardiac dysfunction $(34,35)$. In the present study, the anti-fibrotic properties of bisoprolol in the heart were analyzed. Initially the anti-fibrotic role of bisoprolol was examined through PSR staining of sections from interstitial and perivascular regions of the left ventricles (Fig. 4A-C). In agreement with the results from pathological images and quantification, middle- and high-dose bisoprolol-treated mice demonstrated increased collagen degradation or decreased collagen synthesis in response to tissue damage. However, no statistically significant difference was observed between them. TGF- $\beta_{1}$ has been reported to be one of the main mediators of cardiac fibroblast activation (36) and is considered as a profibrogenic cytokine that contributes to various types of fibrosis, including cardiac fibrosis associated with heart failure $(37,38)$. Studies have demonstrated that the expression of TGF- $\beta_{1}$ is increased in patients with cardiomyopathic conditions and animal models of cardiac fibrosis $(39,40)$. This was firmly verified in the present study by analyzing the protein and mRNA expression levels of the fibrotic markers CTGF, collagen $1 \mathrm{a}$ and TGF- $\beta_{1}$, that are 
known to be important in the biosynthesis of ECM proteins and the proliferation of cardiac fibroblasts (Fig. 4D and E). These results are also consistent with a previous study by Fukui et al (41).

The current study demonstrates that the effects of bisoprolol in the attenuation of ventricular remodeling induced by hypertrophic stimuli are time-dependent. Thus, achieving a target dose of bisoprolol for attenuating ventricular remodeling may not be a preferred option in some cases $(42,43)$. Future studies should focus on determining whether the results obtained in mice are also observed among patients from different regions, and with different professions and states of disease $(44,45)$. The translation of this knowledge into clinical use should be challenging and exciting.

Furthermore, the results of the present study must be evaluated in light of several study limitations. Firstly, the clinical efficacy of different $\beta$-blockers does not appear to be equivalent (29). A previous study suggests that nebivolol, a $\beta_{1}$-selective AR blocker improves LV dysfunction and survival early after myocardial infarction and possibly beyond the effects provided by conventional $\beta_{1}$-receptor blockade (46). Secondly, the sample size was small. Finally, the present study did not assess the findings through the levels of cardiac electrophysiology. Nevertheless, the observations reported in the present study may have clinical significance for the pharmacological modulation of catecholamine-mediated myocardial remodeling in the stressed heart, for example giving the right person the correct medication and dose, and knowing the correct duration of use of the medication.

\section{Acknowledgements}

The authors thank Xiang Gao and Lina Zhou of the Central Laboratory, Renmin Hospital of Wuhan University for technical assistance. This study was supported by the Doctoral Program Foundation of the Department of Education (grant no. 20130141130010), which is used in the field of preferential development in China.

\section{References}

1. Lloyd-Jones D, Adams RJ, Brown TM, Carnethon M, Dai S De Simone G, Ferguson TB, Ford E, Furie K, Gillespie C, et al; American Heart Association Statistics Committee and Stroke Statistics Subcommittee: Executive summary: Heart disease and stroke statistics - 2010 update: A report from the American Heart Association. Circulation 121: 948-954, 2010.

2. Lohse MJ, Engelhardt S and Eschenhagen T: What is the role of beta-adrenergic signaling in heart failure? Circ Res 93: 896-906, 2003.

3. Yang J, Liu Y, Fan X, Li Z and Cheng Y: A pathway and network review on beta-adrenoceptor signaling and beta blockers in cardiac remodeling. Heart Fail Rev 19: 799-814, 2014.

4. Tzingounis AV, von Zastrow $M$ and Yudowski GA: $\{$ Beta\}-blocker drugs mediate calcium signaling in native central nervous system neurons by $\{$ beta $\}$-arrestin-biased agonism. Proc Natl Acad Sci USA 107: 21028-21033, 2010.

5. Gheorghiade M, Albert NM, Curtis AB, Thomas Heywood J, McBride ML, Inge PJ, Mehra MR, O'Connor CM, Reynolds D, Walsh MN, Yancy CW and Fonarow GC: Medication dosing in outpatients with heart failure after implementation of a practice-based performance improvement intervention: Findings from IMPROVE HF. Congest Heart Fail 18: 9-17, 2012.

6. Shen DF, Tang QZ, Yan L, Zhang Y, Zhu LH, Wang L, Liu C, Bian ZY and Li H: Tetrandrine blocks cardiac hypertrophy by disrupting reactive oxygen species-dependent ERK1/2 signalling. Br J Pharmacol 159: 970-981, 2010.
7. Bian Z, Cai J, Shen DF, Chen L, Yan L, Tang Q and Li H: Cellular repressor of E1A-stimulated genes attenuates cardiac hypertrophy and fibrosis. J Cell Mol Med 13: 1302-1313, 2009.

8. Bian ZY, Huang H, Jiang H, Shen DF, Yan L, Zhu LH, Wang L, Cao F, Liu C, Tang QZ and Li H: LIM and cysteine-rich domains 1 regulates cardiac hypertrophy by targeting calcineurin/nuclear factor of activated T cells signaling. Hypertension 55: 257-263, 2010.

9. Novoyatleva T, Schymura Y, Janssen W, Strobl F, Swiercz JM, Patra C, Posern G, Wietelmann A, Zheng TS, Schermuly RT and Engel FB: Deletion of Fn14 receptor protects from right heart fibrosis and dysfunction. Basic Res Cardiol 108: 325, 2013.

10. Noguchi A, Nakamura K, Sakata K, Sato-Fukuda N, Ishigaki T, Mano J, Takabatake R, Kitta K, Teshima R, Kondo K, et al: Development and interlaboratory validation of a simple screening method for genetically modified maize using a $\Delta \Delta \mathrm{Cq}$-based multiplex real-time PCR assay. Anal Chem 88: 4285-4293, 2016.

11. Eghbali $\mathrm{M}$ and Weber KT: Collagen and the myocardium: Fibrillar structure, biosynthesis and degradation in relation to hypertrophy and its regression. Mol Cell Biochem 96: 1-14, 1990.

12. Daniels A, van Bilsen M, Goldschmeding R, van der Vusse GJ and van Nieuwenhoven FA: Connective tissue growth factor and cardiac fibrosis. Acta Physiol (Oxf) 195: 321-338, 2009.

13. Ruiz-Ortega M, Rodríguez-Vita J, Sanchez-Lopez E, Carvajal G and Egido J: TGF-beta signaling in vascular fibrosis. Cardiovasc Res 74: 196-206, 2007.

14. Giordano FJ: Oxygen, oxidative stress, hypoxia, and heart failure. J Clin Invest 115: 500-508, 2005.

15. Belge C, Hammond J, Dubois-Deruy E, Manoury B, Hamelet J, Beauloye C, Markl A, Pouleur AC, Bertrand L, Esfahani H, et al: Enhanced expression of $\beta 3$-adrenoceptors in cardiac myocytes attenuates neurohormone-induced hypertrophic remodeling through nitric oxide synthase. Circulation 129: 451-462, 2014.

16. Heineke J and Molkentin JD: Regulation of cardiac hypertrophy by intracellular signalling pathways. Nat Rev Mol Cell Biol 7: 589-600, 2006.

17. Hill JA and Olson EN: Cardiac plasticity. N Engl J Med 358: 1370-1380, 2008.

18. Drazner MH: The progression of hypertensive heart disease. Circulation 123: 327-334, 2011.

19. Lohse MJ, Engelhardt S and Eschenhagen T: What is the role of beta-adrenergic signaling in heart failure? Circ Res 93: 896-906, 2003.

20. Port JD and Bristow MR: Altered beta-adrenergic receptor gene regulation and signaling in chronic heart failure. J Mol Cell Cardiol 33: 887-905, 2001.

21. Mason RP, Giles TD and Sowers JR: Evolving mechanisms of action of beta blockers: Focus on nebivolol. J Cardiovasc Pharmacol 54: 123-128, 2009.

22. Yang J, Liu Y, Fan X, Li Z and Cheng Y: A pathway and network review on beta-adrenoceptor signaling and beta blockers in cardiac remodeling. Heart Fail Rev 19: 799-814, 2014.

23. McMurray JJ, Adamopoulos S, Anker SD, Auricchio A, Böhm M, Dickstein K, Falk V, Filippatos G, Fonseca C, Gomez-Sanchez MA, et al; ESC Committee for Practice Guidelines: ESC Guidelines for the diagnosis and treatment of acute and chronic heart failure 2012: The Task Force for the Diagnosis and Treatment of Acute and Chronic Heart Failure 2012 of the European Society of Cardiology. Developed in collaboration with the Heart Failure Association (HFA) of the ESC. Eur Heart J 33: 1787-1847, 2012.

24. Writing Committee Members; Yancy CW, Jessup M, Bozkurt B, Butler J, Casey DE Jr, Drazner MH, Fonarow GC, Geraci SA, Horwich T, et al; American College of Cardiology Foundation/American Heart Association Task Force on Practice Guidelines. 2013 ACCF/AHA guideline for the management of heart failure: A report of the American College of cardiology Foundation/American Heart Association task force on practice guidelines. Circulation 128: e240-e327, 2013.

25. Lee DS, Tu JV, Juurlink DN, Alter DA, Ko DT, Austin PC, Chong A, Stukel TA, Levy D and Laupacis A: Risk-treatment mismatch in the pharmacotherapy of heart failure. JAMA 294: 1240-1247, 2005

26. Poldermans D, Boersma E, Bax JJ, et al: Expression of concern relating to: 'Bisoprolol reduces cardiac death and myocardial infarction in high-risk patients as long as 2 years after successful major vascular surgery'. Eur Heart J: doi: 10.1093/eurheartj/ehu397.

27. van der Wall EE: Beta-blocking agents in cardiovascular disease; are they here to stay? Neth Heart J 22: 481-483, 2014. 
28. Imamura T, Kinugawa $\mathrm{K}$, Hatano $\mathrm{M}$, Fujino $\mathrm{T}$, Muraoka $\mathrm{H}$, Inaba T, Maki H, Kagami Y, Endo M, Kinoshita O, et al: Preoperative beta-blocker treatment is a key for deciding left ventricular assist device implantation strategy as a bridge to recovery. J Artif Organs 17: 23-32, 2014.

29. Patel K, Fonarow GC, Ekundayo OJ, Aban IB, Kilgore ML, Love TE, Kitzman DW, Gheorghiade M, Allman RM and Ahmed A: Beta-blockers in older patients with heart failure and preserved ejection fraction: Class, dosage, and outcomes. Int J Cardiol 173: 393-401, 2014

30. Jacob SM, Chandy TT and Cherian VT: Oral bisoprolol improves surgical field during functional endoscopic sinus surgery. J Anaesthesiol Clin Pharmacol 30: 59-64, 2014.

31. Tanaka H, Matsumoto K, Sawa T, Miyoshi T, Motoji Y, Imanishi J, Mochizuki Y, Tatsumi K and Hirata K: Evaluation of global circumferential strain as prognostic marker after administration of $\beta$-blockers for dilated cardiomyopathy. Int J Cardiovase Imaging 30: 1279-1287, 2014

32. Cruickshank JM: Are we misunderstanding beta-blockers. Int J Cardiol 120: 10-27, 2007.

33. Nakaya M, Chikura S, Watari K, Mizuno N, Mochinaga K, Mangmool S, Koyanagi S, Ohdo S, Sato Y, Ide T, et al: Induction of cardiac fibrosis by $\beta$-blocker in $\mathrm{G}$ protein-independent and $\mathrm{G}$ protein-coupled receptor kinase 5/ $\beta$-arrestin2-dependent signaling pathways. J Biol Chem 287: 35669-35677, 2012.

34. Berk BC, Fujiwara K and Lehoux S: ECM remodeling in hypertensive heart disease. J Clin Invest 117: 568-575, 2007.

35. Burchfield JS, Xie M and Hill JA: Pathological ventricular remodeling: Mechanisms: Part 1 of 2. Circulation 128: 388-400, 2013.

36. Porter KE and Turner NA: Cardiac fibroblasts: At the heart of myocardial remodeling. Pharmacol Ther 123: 255-278, 2009.

37. Bujak M and Frangogiannis NG: The role of TGF-beta signaling in myocardial infarction and cardiac remodeling. Cardiovasc Res 74: 184-195, 2007.

38. Huang XR, Chung AC, Yang F, Yue W, Deng C, Lau CP, Tse HF and Lan HY: Smad3 mediates cardiac inflammation and fibrosis in angiotensin II-induced hypertensive cardiac remodeling. Hypertension 55: 1165-1171, 2010.
39. Li JM and Brooks G: Differential protein expression and subcellular distribution of TGFbeta1, beta2 and beta3 in cardiomyocytes during pressure overload-induced hypertrophy. J Mol Cell Cardiol 29: 2213-2224, 1997.

40. Pauschinger M, Knopf D, Petschauer S, Doerner A, Poller W, Schwimmbeck PL, Kühl U and Schultheiss HP: Dilated cardiomyopathy is associated with significant changes in collagen type I/III ratio. Circulation 99: 2750-2756, 1999.

41. Fukui M, Goda A, Komamura K, Nakabo A, Masaki M, Yoshida C, Hirotani S, Lee-Kawabata M, Tsujino T, Mano T and Masuyama T: Changes in collagen metabolism account for ventricular functional recovery following beta-blocker therapy in patients with chronic heart failure. Heart Vessels 31: 173-182, 2016.

42. Lenneman AJ and Birks EJ: Treatment strategies for myocardial recovery in heart failure. Curr Treat Options Cardiovasc Med 16 287, 2014.

43. Lund LH, Benson L, Dahlström U, Edner M and Friberg L: Association between use of $\beta$-blockers and outcomes in patients with heart failure and preserved ejection fraction. JAMA 312 : 2008-2018, 2014

44. Apostolovic S, Stanojevic D, Lainscak M, Gelbrich G, Jankovic-Tomasevic R, Pavlovic M, Djordjevic-Radojkovic D, Salinger-Martinovic S, Putnikovic B, Radovanovic S, et al: Regional differences among female patients with heart failure from the cardiac insufficiency bisoprolol study in ELDerly (CIBIS-ELD). Cardiol J 21: 265-272, 2014.

45. Fazio G, Vernuccio F, Lo Re G, Grutta G and Mongiovì M: Role of bisoprolol in patients with long QT syndrome. Ann Noninvasive Electrocardiol 18: 467-470, 2013

46. Sorrentino SA, Doerries C, Manes C, Speer T, Dessy C, Lobysheva I, Mohmand W, Akbar R, Bahlmann F, Besler C, et al: Nebivolol exerts beneficial effects on endothelial function, early endothelial progenitor cells, myocardial neovascularization, and left ventricular dysfunction early after myocardial infarction beyond conventional $\beta 1$-blockade. J Am Coll Cardiol 57: 601-611, 2011. 